مجلة تطبيقات علوم الرياضة

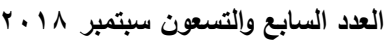

فاعلية منهاج العاب القوى في ضوء الجودة الثاملة وعلاقته بالقيم التربوية من وجهة نظرطلبة الجامعة الهاشمية

رائد محمد الرقاد مهناب

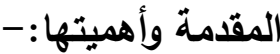

تلعب التربية البذنية والرياضية دوراً هاما في تكوين شخصية الإنسان، ويرجع ذلك في الدقام الأول إلى أوجه النشاط التي تتضمنها مناهجها،

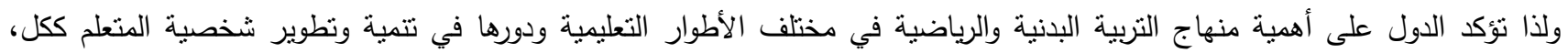
وتحقيق النمو الثامل والمتزن له، وذلك في الجوانب الحس-حركية والمعرفية والوجدانية، إذ يعد المنهاج وسيلة لتحقيق الأهداف التعليمية

والتزبوية للتربية البدنية والرياضية.

يعد التعليم من أهم نهضات الأمم فالدول التي تقدمت اهتمت بالتتمية البشرية التي عمادها إصلاح نظام التعليم، فالتعليم هو أهم وسيلة لبناء الثعوب ومواجهة التغيرات الهائلة والتحديات الكبيرة للمستقبل، وتسعى كل دولة من خلال مؤسساتها التربوية المختلفة محاولة الرقي بأفراد

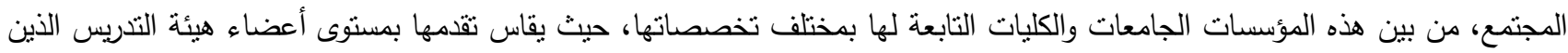
يعملون بها، ولا شك أن تطوير الجامعات وكلياتها المختلفة وتحديثها في هذا العصر يعتبر أهم المنطلبات الأساسية من أجل الإسهام في نقل

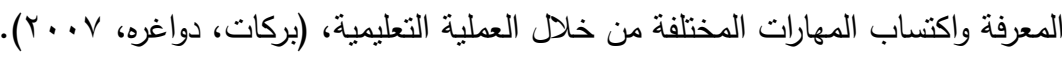
تعد مناهج التربية الرياضية من معالم العملية التربوية التي تهتم بشخصية الفرد وتلبي حاجاته في ضوء المتغيرات الحياتية، وتثبر الدراسات إلى أن المنهاج الحديث ينظم الخبرات والأنشطة ويكسب المتعلم مهارة العمل الجماعي التعاوني، وتؤيد الاتجاهات الإيجابية نحو ما هو مفيد للفرد

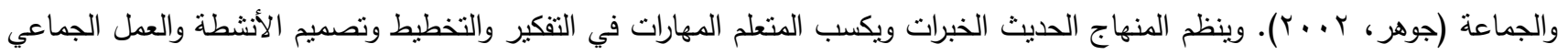
نحو ما هو مفيد للفرد والجماعة متل احترام الآخرين، والإطلاع المستمر، والتعلم الذاتي وحب المعرفة، والتعرف على مصادرها وسبل حل المشكلات، وأساليب عرض النتائج والحلول بأسلوب علمي واضح ليصبح النعليم وظيفياً يرتبط بحياة المتعلم ويدفعه للاستفادة مما يتعلمه

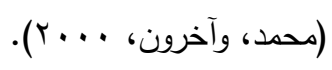

تعد مناهج العاب القوى إحدى فروع تخصص التربية الرياضية إذ أنها نتفرد بخطط مستقلة تساهم في إثراء الفرد بالمعرفة العملية والتطبيقية،

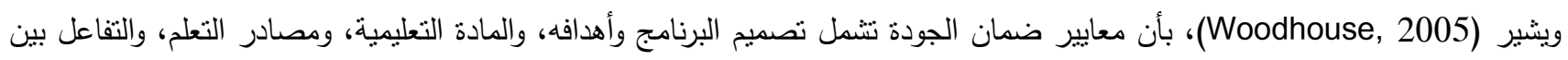
الأستاذ والطالب، وتقويم أداء الطلبة، والإدارة، وتقويم البرنامج، وأخذت كليات التربية الرياضية في الأردن على عاتقها تطوير برامجها التعليمية

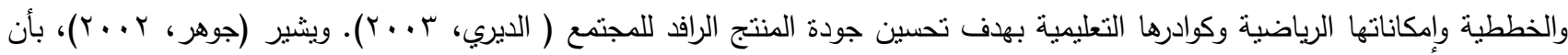
الجودة صفة في المنتج تبين مدى الكفاءة في تحقيق احتياجات المستقيد من الخدمة النعليمية في تحقيق البرامج والأهداف للخرجين، ويؤكد ذلك (الرشيد، . . . ب)، بأن الجودة تعد معياراً أساسيا لتقويم مخرجات التعليم، وتتحدد في تفسير النتائج للتعرف على الإنجازات والإخفاقات الذي يحققه البرنامج التعليمي من خلال المخرجات التعليمية. تعبر القيم عن الاتجاهات التي تتضح من خلال سلوك الفرد الععلي أو اللفظي في المؤسسة التعليمية سواء المدرسة أو الجامعة (حسين،

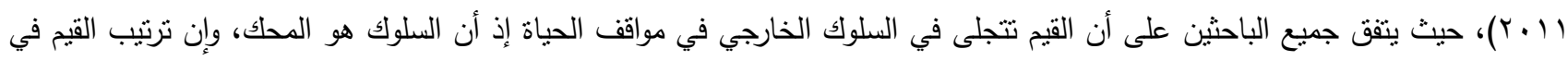
مناهج التربية الرياضية قائم على أساس سلم يختلف من وقت لآخر تبعاً لعدة عوامل وهي الاقتصادية والاجتماعية والدينية والأمنية والتتوع في

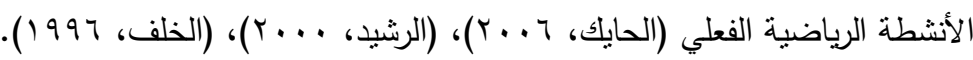




\section{رائد محمد الرقاد}

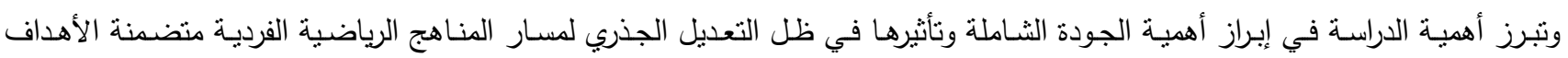

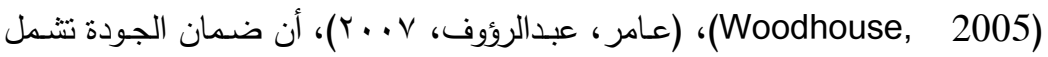

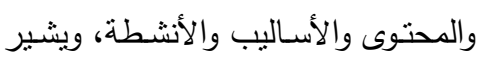
تصميم البرامج والأهداف والتفاعل بين الددرس والطالب، فقد تغيرت منظومـة الحياة في مضمونها ومفاهيمها التربوية في شتى المجالات الاجتماعية والأخلاقية وغيرها من المفاهيم، ولذلك لا بد من مراجعتها، وإعادة تقيمها في مناهجنا الرياضية العملية والنظرية، وان تقيم فاعلية مناهج الألعاب الفردية تتبع لأهمية الدراسة في التعرف على فاعلية مناهج العاب القوى وعلاقته بالقيم التربوية في ضوء الجودة الثشاملة، وتحقيق

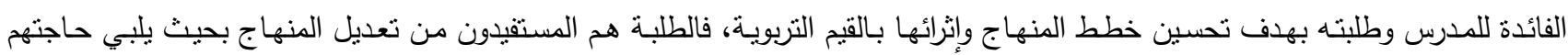
وميولهم بما يتماثشى مع تطورات العصر السريع كما حددتها برامج الجودة الثاملة، وبما أن مساقات العاب القوى ( ()، ومساق العاب قوى(؟)، إحدى مواد التربية الرياضية العملية التي يدرسها الباحث وإنها تتفرد بخطط مستقلة تساهم في إثراء المتعلم بالمعرفة العلمية والنطبيقية، فقد تبادر إلى ذهن الباحث تقيم العلاقة بين منهاج العاب القوى والقيم التزبوية في ضوء الجودة.

\section{مشكلة البحث:-}

تتاول الباحث منهاج العاب القوى وعلاقته بالقيم التزبوية بهدف تقييم العلاقة بينهما حيث أولت المؤسسات التزبوية إلى الاستفادة من برامج الجودة وجعلتها وسيلة لتطوير مناهجها من اجل إعداد وتحسين المتعلم، وان الجودة مجموعة من القيم والمفاهيم والاستراتيجيات والأدوات والمعتقدات والممارسات هدفها تحسين جودة المتعلم (Navartnam \& Oconnor 1993)، حيث اهتمت مناهج التربية الرياضية بالجانب النفس حركي من محتوى وأساليب تدريس ومناهج تدريس أدى إلى ظهور اتجاهات جديدة نركز على الجانب الوجداني من القيم والاتجاهات

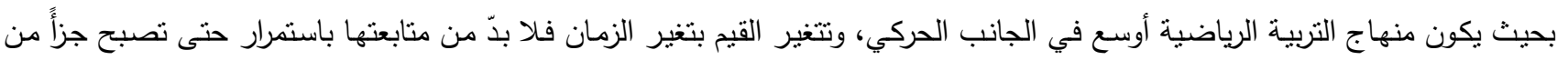

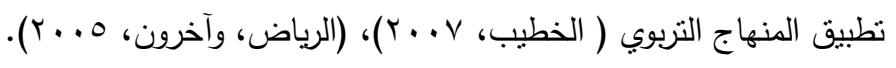

- فاعلية مناهج العاب القوى في ضوء برامج الجودة الثناملة من وجهة نظر طلبة كلية التربية البدنية وعلوم الرياضة في الجامعة الهاشمية. - علاقة مناهج العاب القوى في ضوء برامج الجودة الثاملة بتحقيق القيم التزبوية من وجهة نظر طلبة كليات التربية الرياضية في الجامعة 
- ما تقديرات طلبة كلية التربية البدنية وعلوم الرياضة في الجامعة الهاشمية لفاعلية منهاج العاب القوى في ضوء برامج الجودة الثاملة من حيث الأهداف والمحتوى والأساليب والأنشطة والتقويم ؟ - ما علاقة منهاج العاب القوى في ضوء برامج الجودة الثاملة بالقيم التربوية من وجهة نظر طلبة كلية التربية البدنية وعلوم الرياضة في الجامعة الهاشمية؟ - هل توجد فروق دالة إحصائية لفاعلية منهاج العاب القوى في ضوء برامج الجودة الثاملة تبعاً لمتغير الجنس، ممارسة اللعبة، مستوى المادة؟

\section{مصطحات الدراسة:-}

المنهاج: يعرف بأنه جميع الخبرات التربوية التي تقدما المدرسة والجامعة للتناميذ في الفصل أو خارجه وفق أهداف محددة شريطة أن تكون هذه الخبرات تحت قيادة سليمة تحقق النمو الثشامل المتزن من جميع النواحي الجسمية والعقلية والاجتماعية والنفسية ليتمكن التناميذ من إتقان

$$
\text { المهارات النافعة لهم (الديري، ب. . ب). }
$$

القيم: سلوك لفظي عملي ينمو مع الفرد من خلال تجارب الحياة تتسم بالاعتبارات السيكولوجية والاجتماعية والأخلاقية والجمالية تتعكس على لهى

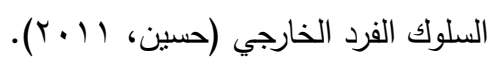

محددات الاراسة:-

المجال المكاني: كلية التربية البدنية وعلوم الرياضة في الجامعة الهاشمية. المجال البشري: طلبة قسم الإدارة والتدريب الرياضي، كلية التربية البدنية وعلوم الرياضة في الجامعة الهانشمية.

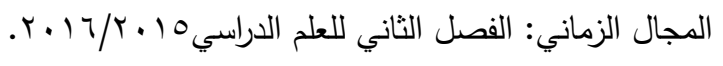

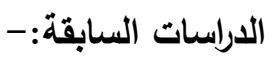

- أجرى (حسين، 1) (1)، دراسة هدفت إلى التعرف على تقويم فاعلية مجالات مناهج الألعاب الجماعية في ضوء برامج الجودة الثاملة

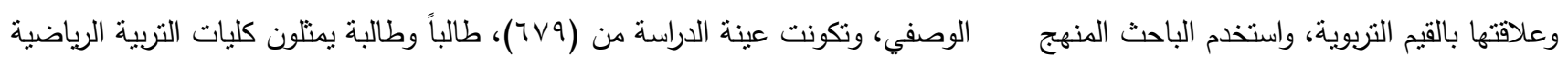

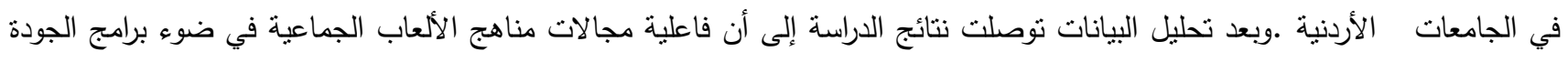
الثاملة جاءت بين درجة عالية جداً، وعالية، وبينت النتائج أن هناك علاقة إيجابية بين مجالات مناهج الألعاب الجماعية ومعظم مجالات القيم

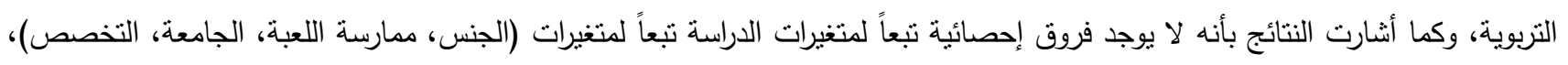
وأن هناك فروق دالة إحصائياً تبعاً لمتغير الجامعة ولصالح طلبة كلية التربية الرياضة في الجامعة الأردنية بالمقارنة مع كليات التربية الرياضية في الجامعات الأخرى، وكذلك وجود فروق دالة إحصائياً تبعاً لمنغير التحصيل الدراسي لصالح الطلبة ذوب النقدير المثناز بالمقارنة مع الطلبة ذوي التقدير الأقل. - أجرى (حسين، الحايك، 9 . . ب)، دراسة هدفت إلى معرفة مدى فاعلية مناهج الكرة الطائرة في ضوء برامج الجودة الثاملة وعلاقتها بالقيم التربوية لطلبة كلية التربية الرياضية في الجامعة الأردنية، واستخدم الباحث المنهج الوصفي، وتكونت عينة الدراسة من ( (1 )، طالباً وطالبة،

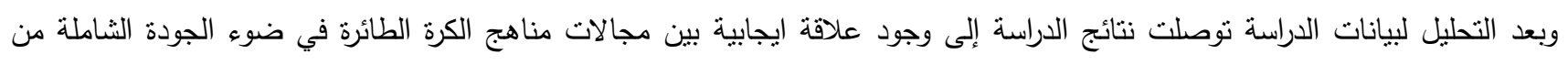
وجهة نظر الطلبة وجميع مجالات القيم التربوية، وأن فاعلية مناهج الكرة الطائرة جاءت بدرجة عالية جداً في جميع المجالات ( الأهداف، والمحتوى، الأساليب والأنشطة، والتقويم)، وعدم وجود فروق ذات دلالة إحصائية تبعا لمتغير الجنس، ومتغير ممارسة اللعبة في جميع مجالات مناهج الكرة الطائرة من وجهة نظر الطلبة، ووجود فروق بين المنوسطات الحسابية تبعا لمتغير المادة في مجال الأهداف ولصالح الطلبة الذين 
درسوا الكرة الطائرة (ץ). وأصت الدراسة إلى ضرورة تطوير الهناهج ببرا مج الجودة الثاملة لتحقيق القيم التربوية في جميع مجالات التربية الرياضية.

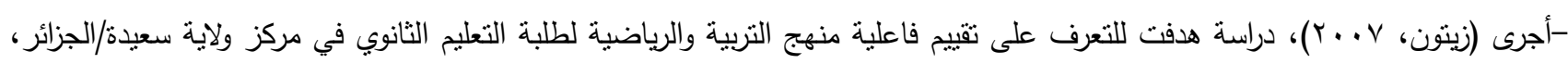

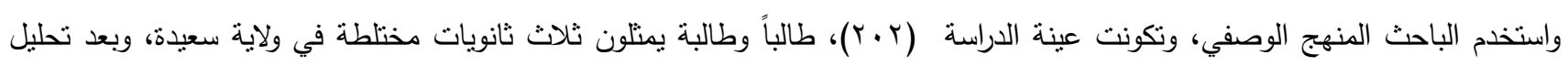
البيانات نوصلت نتائج الدراسة إلى ضعف البعد المعرفي لعينتي الدراسة في اختبارات المعلومات والمعارف والفهم في مجال التربية البننية والرياضية، كما أظهرت الاختبارات الحس- حركية ببعديها الاثثين البدني- المهاري )، والمعرفية كفاءات عالية في تقييم نتائج التعليم

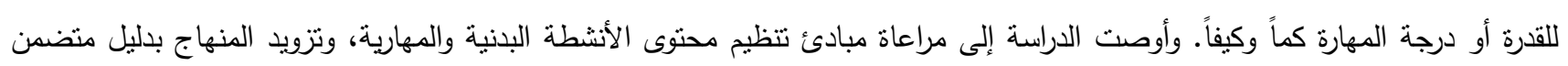

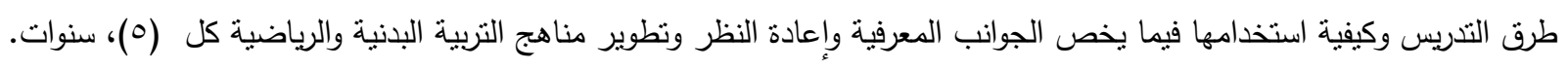

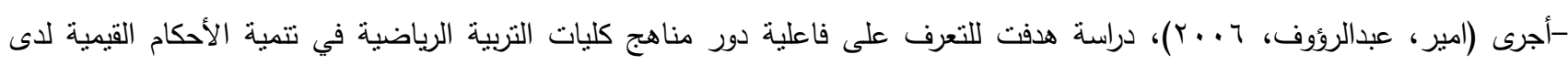

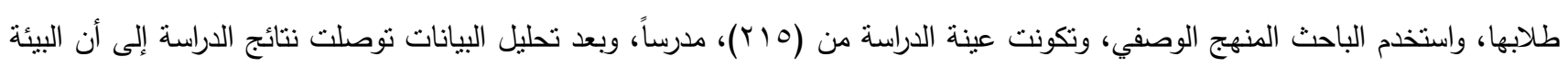
الجامعية هي أكثر العوامل فعالية في تتمية القيم الخلقية والدينية وان هناك العديد من المشكلات السلوكية والقضايا الاجتماعية التي تدعو إلى إلى

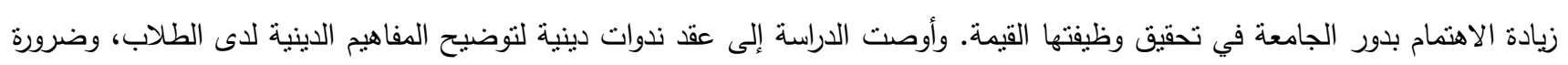
تدريس الفلسفة الرياضية من الوجهة الدينية كمادة أساسية في البكالوريوس والدراسات العليا.

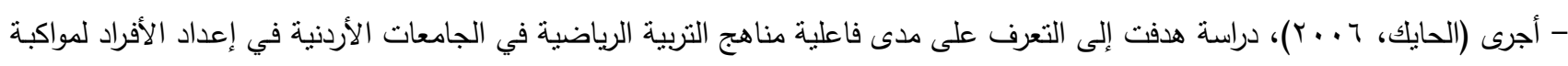

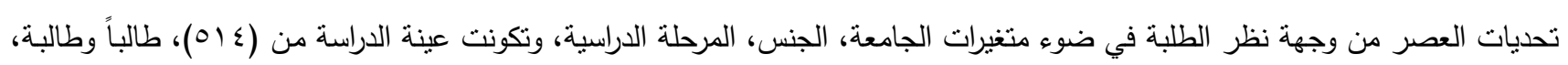

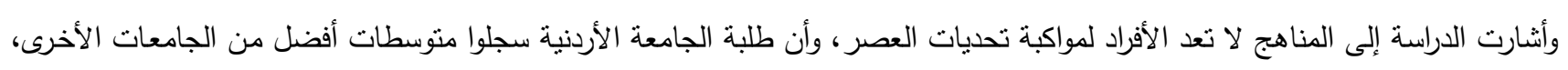
ولم تجد إثنارة تعزى لمستوى الجنس.

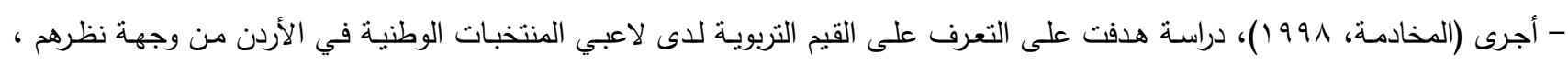

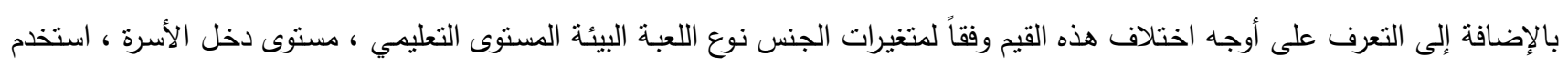

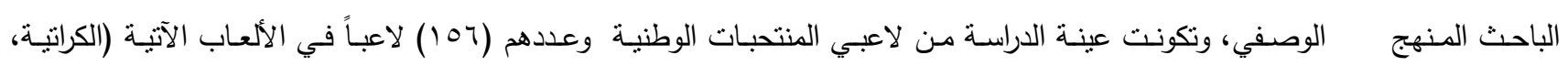

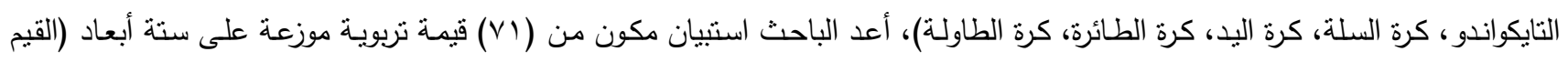

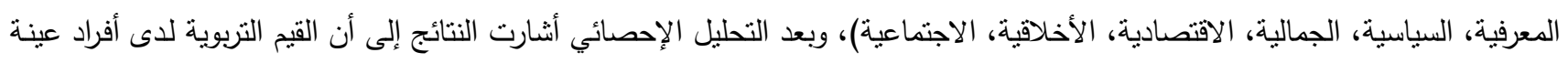

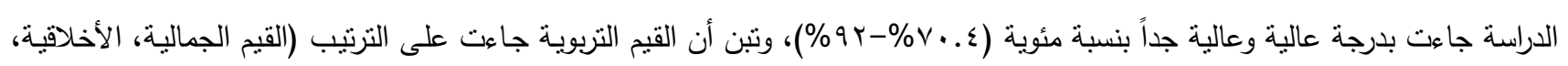

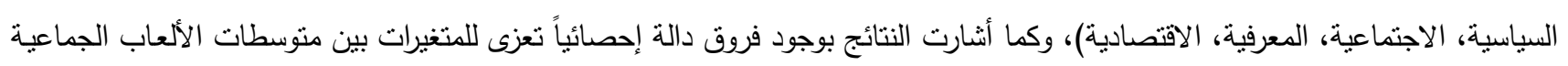

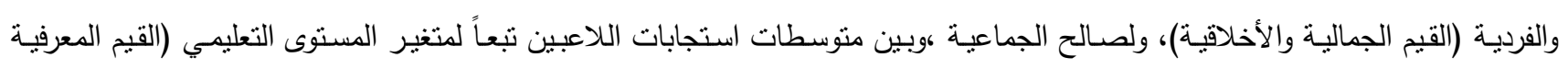
والأخلاقية)، لصالح الجامعيين. - أجرى (الخلف، و99 (1)، بدراسة هدفت إلى التعرف على القيم التربوية الواجب نوافرها لاى طلبة كلية التربية الرياضية من وجهة نظرهم

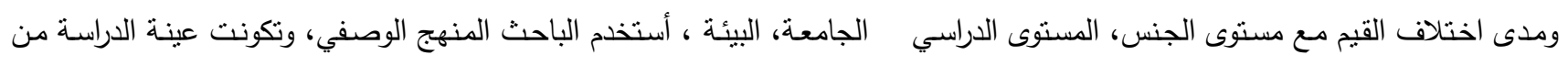

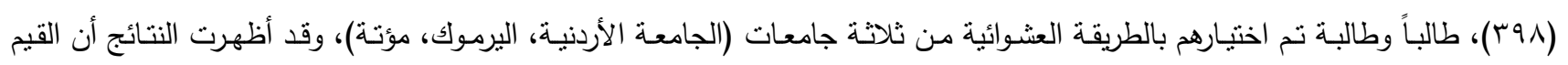

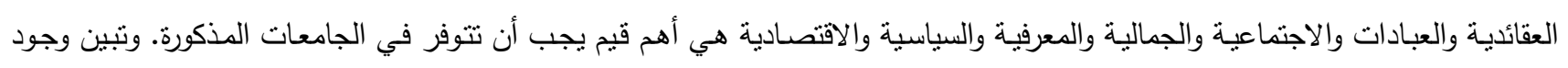

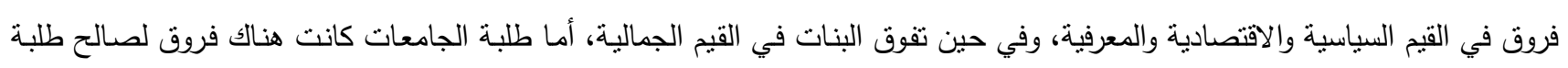
مؤتة في السنة الثانية، وطلبة المدينة في أبعاد القيم السبعة. 


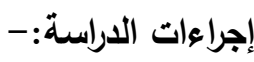

- منهج الدراسة:-

استخدم الباحث المنهج الوصفي •

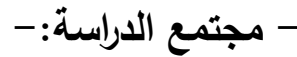

تكون مجتمع الدراسة من طلبة كلية التربية البدنية وعلوم الرياضة، قسم الإدارة والتدريب الرياضي في الجامعة الهاشمية وعددهم (9 ؟ ( طالباً وطالبة.

جدول (1)

توزيع أفراد مجتمع الدراسة لكلية التربية البدنية وعلوم الرياضة في الجامعة الهاشمية

\begin{tabular}{|c|c|c|c|c|c|}
\hline المجموع & إناث & ذكور & القسم & الكلية & الجامعة \\
\hline$v \leqslant q$ & rOA & $\{91$ & قسم الإدارة والتدريب & ولية التربية البدنية & الجامعة \\
\hline
\end{tabular}

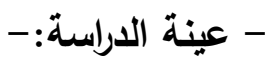

تكونت عينة الدراسة من طلبة كلية التربية البدنية وعلوم الرياضة، قسم الإدارة والتدريب الرياضي في الجامعة الهاشمية، وعددهم (0 ـ () طالب وطالبة أب ما نسبته (ع (\%) من مجتمع الدراسة موزعين على شعب العاب القوى.

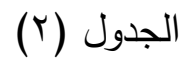

توزيع أفراد العينة حسب متغيرات الدراسة

\begin{tabular}{|c|c|c|c|}
\hline النسبة المئوية & التكرار & \multicolumn{2}{|c|}{ المتغير } \\
\hline$\% 79$ & Vr & ذكور & \multirow[t]{2}{*}{ الجنس } \\
\hline \%rr & Tr & إناث & \\
\hline$\% 1$. & 1. & ممارس & \multirow[t]{2}{*}{ ممارسة اللعبة } \\
\hline$\% q$. & 90 & غير ممارس & \\
\hline$\% \vee q$ & Ar & العاب قوى 1 & \multirow[t]{2}{*}{ مستوى المادة } \\
\hline$\%$ Y & YY & العاب قوى r & \\
\hline
\end{tabular}




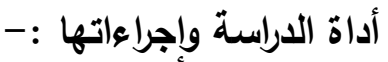

- بعد الاطلاع على الأدب النظري والدراسات السابقة أستطاع الباحث أن يعد استنيان لجمع المعلومات بعد الرجوع إلى الدراسات والأبحاث

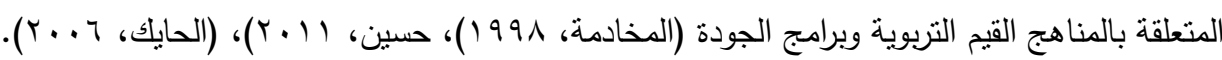

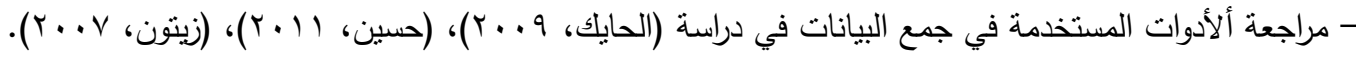
- أعد الباحث الصيغة الأولية للاتتيان وعرضها على الدحكمين من حملة درجة الدكتوراه في التربية الرياضية للتأكد من مناسبتها لعينة

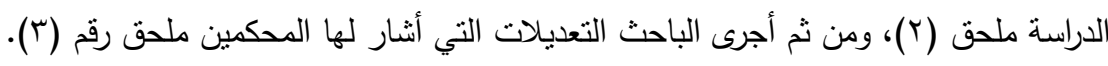
- تكونت الدراسة من جزئين :

الجزء الأول: منهاج العاب القوى (مجال الأهداف، مجال المحتوى، مجال الأساليب والأنشطة، مجال التقويم). الجزء الثاني: القيم التربوية (مجال قيم الانتماء، مجال القيم المعرفية، مجال القيم الأخلاقية، مجال القيم الاجتماعية).

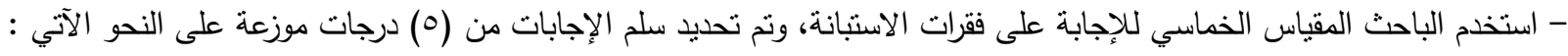
| - مرجة عالية جداً (0) درجات.

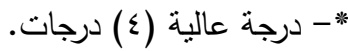
* * درجة متوسطة (ץ) درجات.

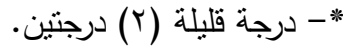
* - مرجة قليلة جداً ( ) (1) درجة.

- نم تفسير النتائج اعتمداً على النسبة المئوية لتقدير درجة فاعلية المنهاج والقيم التربوية وفقاً لبعض المراجع (المخادمة،1991)، (حسين،

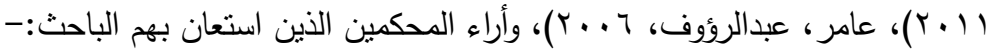

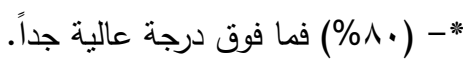

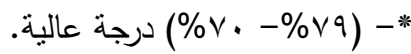

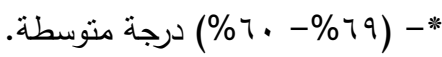

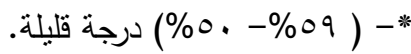

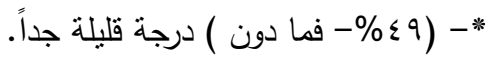
المعاملات العلمية للاراسة :-

- صدق المحتوى: نم عرضة على هيئة من المحكمين والخبراء في مجال التربية الرياضية وعددهم (ع) محكمين والملحق رقم ( () يبين هيئة التحكيم والهدف من ذلك:* تحديد أبعاد منهاج العاب القوى ( ألأهداف، المحتوى، الأساليب والأنشطة، التقويم ). * تحديد أبعاد القيم التنربوية (الاتنماء، المعرفية، الأخلاقية، الاجتماعية).

معامل الثبات:- نم حساب معامل الثبات للاستبيان بطريقة التطبيق وإعادة التطبيق على عينة من أفراد المجتمع وعددهم (•r)، طالبا وطالبة، والفرق بين النطبيقين أسبوعين وتم استبعادهم من عينة الدراسة الأصلية. 
(r) الجدول (r) (20)

معاملات الثبات لـجالات المنهاج

\begin{tabular}{|c|c|c|c|c|c|}
\hline \multirow[t]{2}{*}{ معامل الثبات } & \multicolumn{2}{|c|}{ التطبيق الثاني } & \multicolumn{2}{|c|}{ التطبيق الأول } & \multirow[t]{2}{*}{ المجالات } \\
\hline & $\varepsilon$ & س س & $\varepsilon$ & س س & \\
\hline.$\wedge 9$ & .99 & E.YY & .99 & $\varepsilon . \leqslant 7$ & الأهداف \\
\hline$\cdot . \wedge \vee$ & $\because V Y$ & $\varepsilon . Y$. & $\because 9$. & $\varepsilon . r_{0}$ & المحتوى \\
\hline.$\wedge \varepsilon$ & $.9 V$ & $\varepsilon \ldots$ & $\cdot . \wedge \wedge$ & $r .99$ & الأساليب والأنشطة \\
\hline.$\wedge r$ & .10 & $\varepsilon . \cdot r$ &. .19 & $\varepsilon . r$. & التقويم \\
\hline. .17 & $\cdot . \wedge \wedge$ & $\varepsilon .1 T$ & $\cdot .9$. & E.ro & المجال الكلي \\
\hline
\end{tabular}

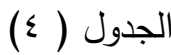

معاملات الثبات لمجالات القيم التربوية

\begin{tabular}{|c|c|c|c|c|c|}
\hline \multirow[t]{2}{*}{ معامل التبات } & \multicolumn{2}{|c|}{ التطبيق الثاني } & \multicolumn{2}{|c|}{ التطبيق الأول } & \multirow[t]{2}{*}{ المجالات } \\
\hline & $\varepsilon$ & س س & $\varepsilon$ & س س & \\
\hline . . & .00 & $\varepsilon . .9$ &. $.7 \mathrm{~V}$ & $\varepsilon . . r$ & قيم الاتتماء \\
\hline$\cdot \wedge$ & .7 & $\{.17$ &.$\wedge r$ & $\varepsilon .11$ & القيم المعرفية \\
\hline$\therefore \vee \wedge$ & $.7 V$ & $\varepsilon .11$ &. $.7 \mathrm{~V}$ & S.r & القيم الأخلاقية \\
\hline$\cdot . \wedge 1$ &..$\wedge \wedge$ & $\varepsilon . \cdot V$ &. .77 & $r .99$ & القيم الاجتماعية \\
\hline.$\wedge 1$ & .71 & s.lT &.$v 1$ & 5.11 & المجال الكلي \\
\hline
\end{tabular}

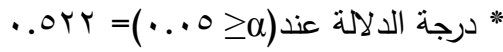
المعالجات الإحصائية:

استخدم الباحث نظام التحليل الإحصائي (SPSS) - الوسط الحسابي،الانحراف المعياري، النسبة المئوية.

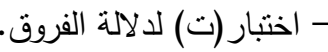
- نحليل التباين الأحادي (ANOVA) لمتغيرات الدراسة . عرض النتائج ومناقشتها:للإجابة على التساؤل الأول:- ما تقديرات طلبة كلية التربية البذنية وعلوم الرياضة في الجامعة الهاشمية لفاعلية منهاج العاب القوى في ضوء برامج الجودة الثاملة من حيث مجالات ( الأهداف، والمحتوى، والأساليب والأنشطة، التقويم )، تم استخراج الوسط الحسابي 
والانحراف المعياري والنسب المئوية للتعرف على اتجاهات العينة نحو فقرات القياس حيث تم التوصل إلى النتائج التالية جدول رقم (•)،

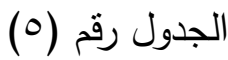

متوسطات الحسابية والنسبة المئوية لتقديرات الطلبة على فقرات الأهداف

\begin{tabular}{|c|c|c|c|c|}
\hline النسبة & $\varepsilon$ & س & 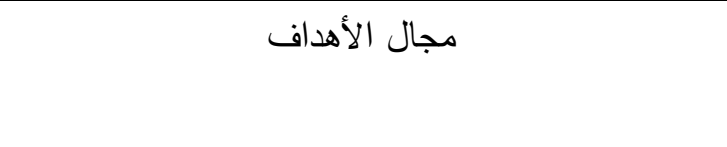 & 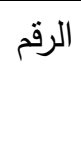 \\
\hline$\% \vee 0$ &.$V V$ & r.vo & تلتبثق أهداف مساقات العاب القوى من فلسفة كلية & 1 \\
\hline$\% \vee 0.7$ & .90 & r.vA & تهدف المساقات إلى تطوير السمات الثخصية & r \\
\hline$\% \wedge \cdot . \varepsilon$ &..$\wedge \varepsilon$ & $\varepsilon .+r$ & تهذف المساقات إلى اكتساب الطالب مهارات معرفية & r \\
\hline$\% \wedge r . \varepsilon$ &.$V r$ & $\varepsilon .1 \mathrm{~V}$ & تهدف المساقات إلى نطبيق المهارات الأساسية & $\varepsilon$ \\
\hline$\% \vee \vee$ & $\cdot . \wedge \mathrm{V}$ & r.^o & تهدف المساقات إلى تعزيز الميول والدوافع عند الطلبة & 0 \\
\hline$\% \wedge$. & .94 & $\varepsilon \ldots$ & تهالعاب القوى المسات إلى تطبيق برامج التدريب الرياضي & 7 \\
\hline$\% \vee \wedge .7$ & $\cdot .10$ & $r .94$ & 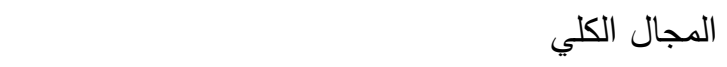 & \\
\hline
\end{tabular}

يشير الجدول (0)، إلى أن اتجاهات العينة ايجابية نحو فقرات الأهداف، وتبين أن الفقرة (ع)، (تهدف المساقات إلى تطبيق المهارات الأساسية

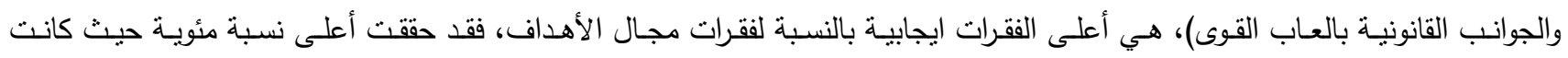

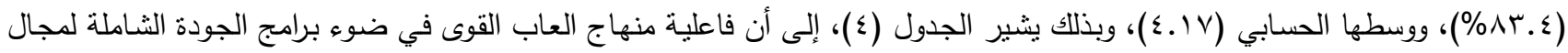
الأهداف كان عالياً. ويفسر الباحث أن مثل هذه النتائج تعود إلى وضوح الأهداف وقابليتها للقياس وموائيتها للبيئة المحلية، وجاءت هذه النتائج

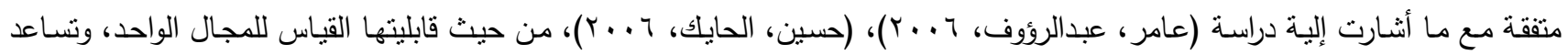
المدرس في معرفة ما تحقق من الأهداف واستتادها إلى فلسفة تربوية، وأسس سيكولوجية واجتماعية سليمة ومرنة قابلة للتقييم المستمر في ضوء برامج الجودة الثاملة حتى تنقى ناجحة في أداء وظيفتها وشاملة ومترابطة في إطار متكامل، وجميع هذه الثروط كانت منوفرة في المنهاج، وظهر ذلك من خلال استجابة عينة الدراسة على مجال الأهداف، وان برامج التدريب تتعامل مع قدرات بدنية ومهارية في العاب القوى. 


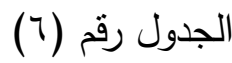

المتوسطات الحسابية والنسبة المئوية لتقديرات الطلبة على فقرات المحتوى

\begin{tabular}{|c|c|c|c|c|}
\hline المئوبة & $\varepsilon$ & س س & 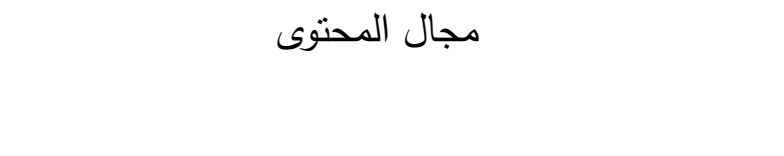 & 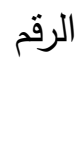 \\
\hline$\% \vee 9.7$ & .99 & r.91 & العاب القوى المناهج في تطوير البنية المعرفية في مجال & 1 \\
\hline$\% \vee 4$ &. $.9 \vee$ & r.A. & وبتتاسب المحتوى مع الإمكانات المتاحة في كلية التربية & r \\
\hline$\% \wedge$ \% ร &.$\wedge$. & 纟.rT & تتضمن المناهج المهارات الأساسية بالعاب القوى & r \\
\hline$\% \vee r$ & .90 & r.५. & يعمل على تحسين مستوى اللياقة البدنية & $\varepsilon$ \\
\hline$\% \uparrow \varepsilon$ & $\cdot 91$ & r.r. & يواكب المحتوى المنهاج التطور العلمي & $\circ$ \\
\hline$\% 74.7$ & $1 .+r$ & r.rr & يرتبط محتوى منهاج العاب القوى بالعلوم الرياضية & 7 \\
\hline$\% \vee \leqslant .1$ & $\cdot .94$ & r.v & 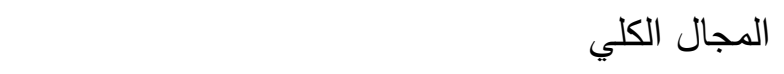 & \\
\hline
\end{tabular}

أما بالنسبة إلى مجال المحتوى فيبين الجدول (؟)، أن الفقرة (تتضمن المناهج المهارات الأساسية بالعاب القوى) هي أعلى

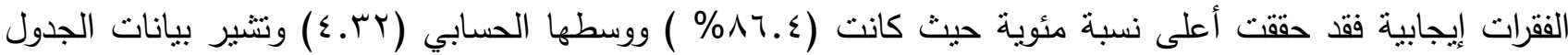
رقم (0)، إلى أن فاعلية منهاج العاب القوى في ضوء برامج الجودة الثاملة لهجال المحتوى كانت عالية جداً وعالية

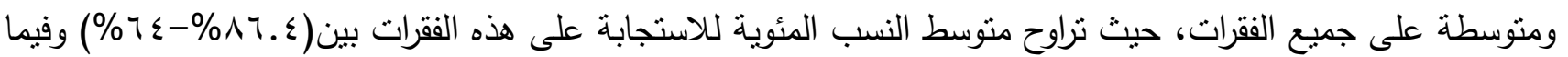

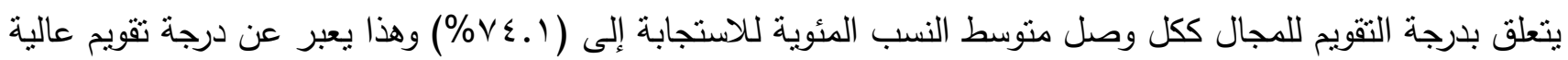
على هذا المجال، ويفسر الباحث أن نتائج مجال الدحتوى جاءت متنقة مع ما أثنارت إليه دراسات (المخادمة، 991 ())،

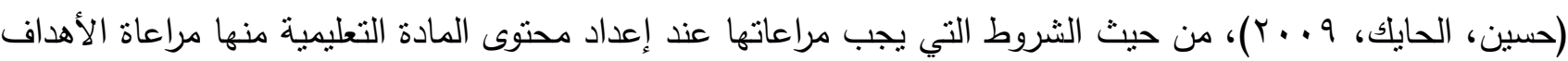
العامة والنواحي النفسية والمعرفية والمهارية والقيم التربوية. وجميع هذه الثروط توفرت في الدنهاج الحالي، وظهر ذلك من خلال استجابة عينة الدراسة حيث كان متوسط النسب المئوية للاستجابة ( ـ \& \% ) )، وهذا يعبر عن درجة عالية، ويمنل جانب قوة للمنهاج الحالي في ضوء الجودة الثناملة لمجال المحتوى. 


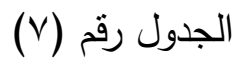

منوسطات الحسابية لتقديرات الطلبة على فقرات الأساليب والأنشطة

\begin{tabular}{|c|c|c|c|c|}
\hline 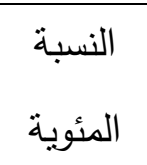 & $\varepsilon$ & س & الأساليب والأنشطة & 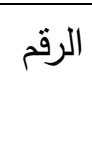 \\
\hline$\% \vee 4 . r$ &.. $\mathrm{vo}_{0}$ & r.人) & تراعي الأساليب والأنشطة الفروق الفردية بين الطلبة & 1 \\
\hline$\% \pi v . \wedge$ &. .90 & r.rq & تتمي مهارات التعلم الذاتي & r \\
\hline$\% \vee r . \varepsilon$ &. .99 & r.TV & المحاضرات وسائل متتوعة تتتاسب مع قدرات الطلبة في & r \\
\hline$\% \vee 0.1$ &. .91 & r.va & يستخدم أساليب حديثة في المحاضرات & $\varepsilon$ \\
\hline$\% 79.1$ &. .91 & r. & الأساليب والأنشطة مرنة وقابلة للتطوير & $\circ$ \\
\hline$\% 70 . \varepsilon$ &. $.9 V$ & r.rV & يتميز النشاط بتقارير مكتبية أو تكنولوجية & 1 \\
\hline$\% \vee 1 . \varepsilon$ & $.9 \varepsilon$ & r.०V & 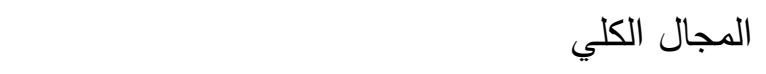 & \\
\hline
\end{tabular}

أما بالنسبة إلى مجال الأساليب والأنشطة فيبين الجدول (V)، أن الفقرة ( تراعي الأساليب والأنثطة الفروق الفردية بين

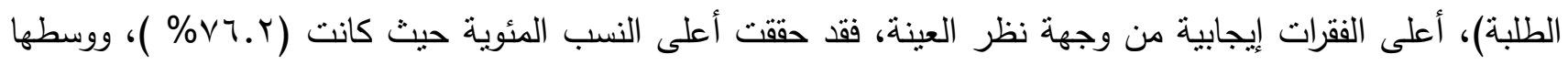

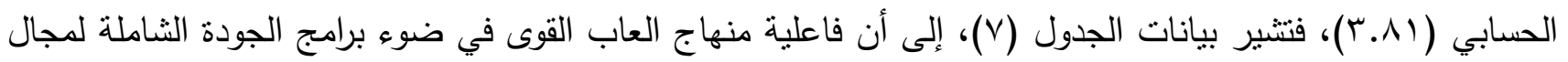
الأساليب والأنشطة كانت عالية ومتوسطة على جميع الفقرات حيث تراوح منوسط النسب المئوية للاستجابة على هذه

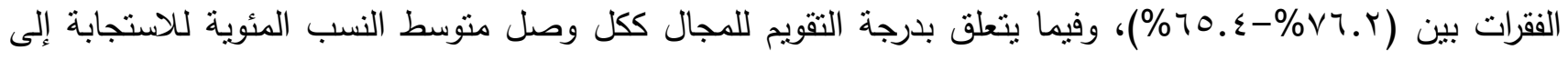

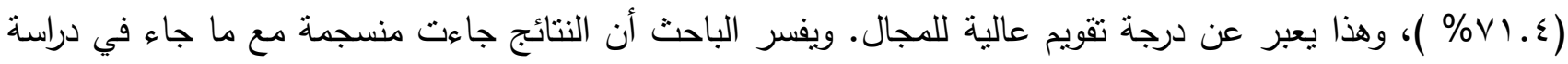

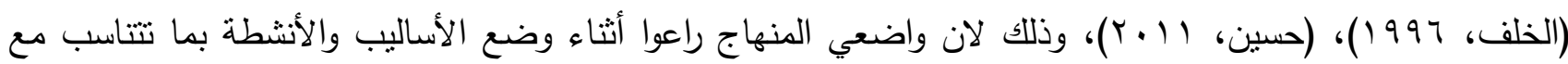
الأساليب المتتوعة للقياس والوسائل التعليمية القريبة لإدراك الطالب وقدراته على ممارسة النشاط الرياضي الجامعي في ضوء الجودة الثاملة، ولذلك جاءت استجابة عينة الدراسة على هذا المجال بدرجة عالية. 


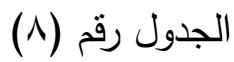

متوسطات الحسابية والنسبة المئوية لتقديرات الطلبة على فقرات التقويم

\begin{tabular}{|c|c|c|c|c|}
\hline المئوية & $\varepsilon$ & س & 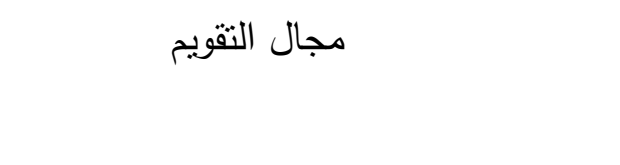 & 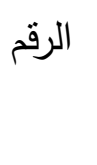 \\
\hline$\% \vee 0 . \varepsilon$ & $.9 \mathrm{~V}$ & T.VV & الحكم على ددى مناسبة محتوى المناهج & 1 \\
\hline$\% \vee \wedge$ &. .10 & r.9. & تراعي الفروق الفردية & r \\
\hline$\% \vee \neg . Y$ & .94 & r.یI & التقويم براعي الثمولية في مفردات المنهاج & $r$ \\
\hline$\% \vee \neg . \varepsilon$ & .99 & r.Ar & يتيح فرصة التقويم الذاتي & $\varepsilon$ \\
\hline$\% \wedge \cdot . \varepsilon$ & 1.00 & $\varepsilon . . r$ & أسلوب التقويم يتتاسب مع إمكانات التدريس & o \\
\hline$\% \vee r . r$ & $1 . . r$ & T.74 & تركز على الاختبارات العطلية والمعرفية & 7 \\
\hline$\% \vee 7.7$ &. .97 & r.یr & لمي & 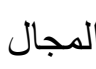 \\
\hline
\end{tabular}

أما بالنسبة إلى مجال النقويم فيبين الجدول (^)، أن الفقرة رقم (0)، (أسلوب التقويم يتتاسب مع إمكانات الندريس) هي أعلى الفقرات إيجابية فقد حققت أعلى نسبة مئوية حيث كانت (ع .1^\%)، ووسطها الحسابي (ץ ..ء)، وفيما ينعلق بدرجة تقويم المنهاج في ضوء الجودة الثاملة لمجال التقويم، وصل متوسط النسبة المئوية للاستجابة للمجال (7.7\%\%)، وهذا يعبر عن درجة تقويم عالية، وجاءت النتائج على هذا المجال جيدة كما هو مبين في الجدول رقم (^). ويفسر الباحث أن لعان

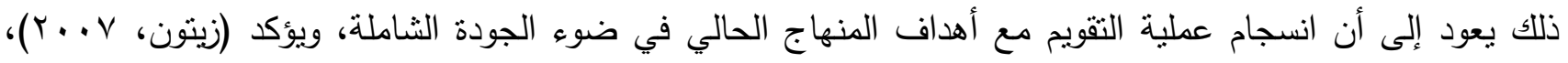

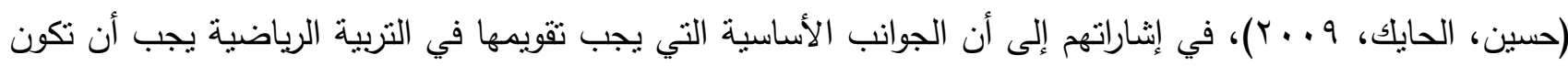

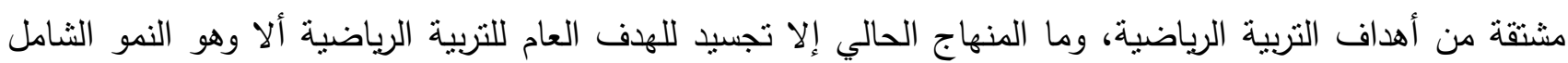
والمتزن لفلسفة المؤسسة التعليمية والجوانب المعرفية والحركية والاجتماعية عند ممارسة النشاط الرياضي. السؤال الثاني- ما هي درجة علاقة منهاج العاب القوى بالقيم التريوية من وجهة نظر طلبة كلية التربية البنية وعلوم

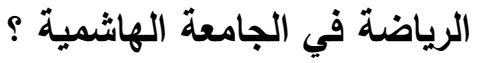




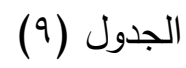

العلاقة بين مجالات منهاج العاب القوى ومجالات والقيم التزبوية

\begin{tabular}{|c|c|c|c|c|}
\hline الاجتماعية & الأخلاقية & المعرفية & الانتماء & المجالات \\
\hline$*$ *.rVo & *..rTV & $* . . \leqslant 94$ & $* .+r) 4$ & مجال الأهداف \\
\hline$*$ *.I & $*$ *,$r \leqslant$. & $* . . \leqslant \vee \leqslant$ & *. & مجال المحتوى \\
\hline$* . .190$ & *. . rAY & 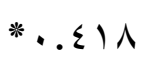 & $* . r \leq \tau$ & مجال الأساليب والأنشطة \\
\hline$* . r r$ & *. . Y०O & *.rqV & *.rrVA & مجال التقويم \\
\hline
\end{tabular}

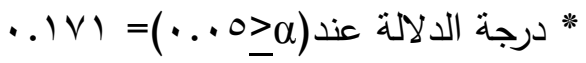

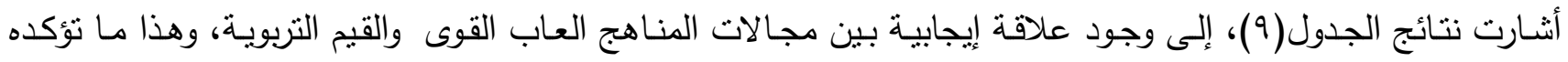

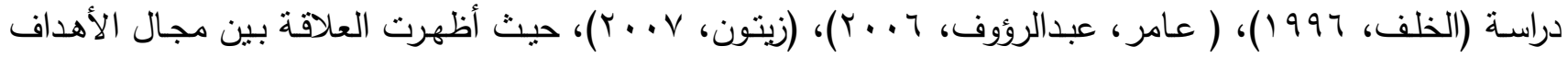

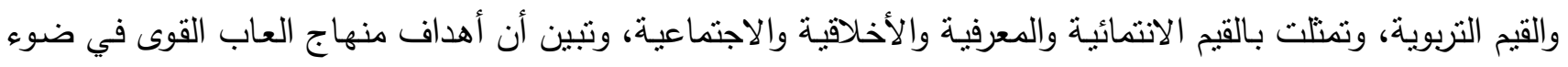

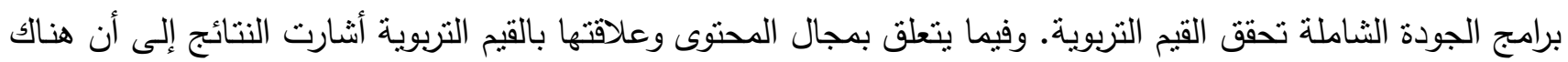
علاقة إيجابية بين محتوى منهاج العاب القوى في ضوء برامج الجودة الثشاملة وجميع مجالات القيم التربوية، ويمكن تفسير هذه العلاقة إلى ما تضمنه المحتوى من قيم تربوية مما انعكس بنواحي إيجابية على الطلبة من قيم معرفية واجتماعية

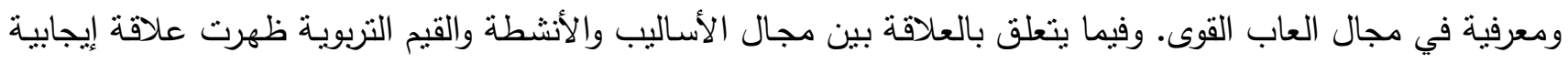

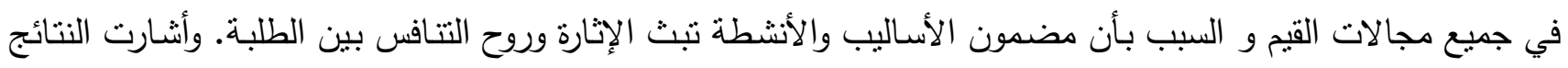

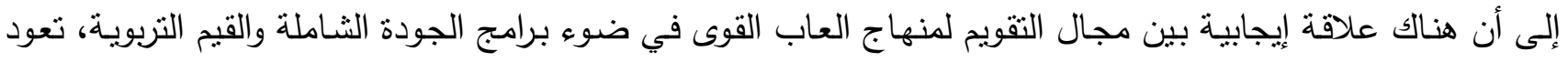
هذه العلاقة إلى أسلوب النقويم حيث يراعي تطبيق الاختبارات البدنية والمهارية والمعرفية ويتتاسب مع إمكانات التدريس

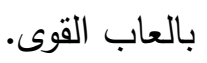

السؤال الثالث- هل توجد فروق دالـة إحصائياً لفاعلية منهاج العاب القوى في ضوء برامج الجودة الثـاملة تبعاً لمتغير(الجنس، ممارسة اللعبة، مستوى المادة )؟ 


\section{جدول (·)}

درجة الفروق لقيمة (ت) نبعاً لمتغير الجنس في ضوء فاعلية منهاج العاب القوى

\begin{tabular}{|c|c|c|c|c|c|}
\hline مستوى الدلالة & قيمة & $\varepsilon$ & س & ذكر (أنثى (سY) & المتغيرات \\
\hline \multirow[t]{2}{*}{ غير دال } & \multirow[t]{2}{*}{. $.1 \mathrm{~V}$} & .94 & r.VV & ذكر & \multirow[t]{2}{*}{ مجال الأهداف } \\
\hline & & .Ar & r.79 & أنثى & \\
\hline \multirow[t]{2}{*}{ غير دال } & \multirow[t]{2}{*}{. .11} & .91 & r.r. & ذكر & \multirow[t]{2}{*}{ مجال المحتوى } \\
\hline & & .90 & r.11 & أنثى & \\
\hline \multirow[t]{2}{*}{ غير دال } & \multirow[t]{2}{*}{. .11} & $1 . . r$ & r.ד & ذكر & \multirow[t]{2}{*}{ مجال الأساليب والأنشطة } \\
\hline & & .99 & r.૫. & أنثى & \\
\hline \multirow[t]{2}{*}{ غير دال } & \multirow[t]{2}{*}{.$r V$} & 1.99 & r.09 & ذكر & \multirow[t]{2}{*}{ مجال التقويم } \\
\hline & & $1 . \wedge \varepsilon$ & T.TV & أنتى & \\
\hline
\end{tabular}

قيمة (ت) الجدولية عند مستوى الدلالة (0>0 . . •)= ؟ 9.9

تشير نتائج الجدول (• ()، بأنه لا توجد فروق دالة إحصائية تعزى لمتغير الجنس في جميع مجالات مناهج العاب القوى، ويمكن تفسير ذلك إلى أن الطـلاب والطالبات الذين درسوا مسـاقات العاب القوى درسوا مناهج موحدة في ضوء بـرامج الجودة الثـاملة لذلك ظهرت إجابـات منقاربـة لجميع مجالات المنـاهج، وجاءت الدراسـة منققة مـع مـا أثـارت إليه دراسـة

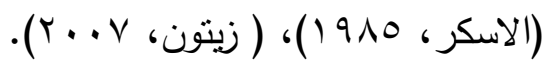


جدول (1)

درجة الفروق لقيمة (ت) تبعاً لمتغير ممارسة اللعبة في ضوء فاعلية منهاج العاب القوى

\begin{tabular}{|c|c|c|c|c|c|}
\hline مستوى الدلالة & قيمة & $\varepsilon$ & س & غير ممارس(90(1) (90) & المتغيرات \\
\hline \multirow{2}{*}{ غير دال } & \multirow[t]{2}{*}{ דיח. } &. To & $r .10$ & ممارس & \multirow{2}{*}{ مجال الأهداف } \\
\hline & &..$\wedge \mathrm{V}$ & r.1) & غير ممارس & \\
\hline \multirow[t]{2}{*}{ غير دال } & \multirow[t]{2}{*}{. IV } & $1 . V \varepsilon$ & T.Tr & ممارس & \multirow[t]{2}{*}{ مجال المحتوى } \\
\hline & & 1.47 & T.TV & غير ممارس & \\
\hline \multirow[t]{2}{*}{ غير دال } & \multirow[t]{2}{*}{$.0 r$} & $1 . \wedge \mathrm{V}$ & T.Vo & ممارس & \multirow{2}{*}{ والأنشطة الأساليب } \\
\hline & & 1.20 & T.Or & غير ممارس & \\
\hline \multirow[t]{2}{*}{ غير دال } & \multirow[t]{2}{*}{..$\leqslant 1$} & 1.14 & $r .00$ & ممارس & \multirow[t]{2}{*}{ مجال التقويم } \\
\hline & &. .17 & T.TT & غير ممارس & \\
\hline
\end{tabular}

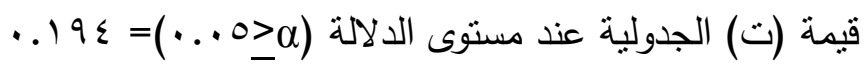

يوضح الجدول(1) النتائج الإحصائية لمتغير ممارسة اللعبة بأنه لا توجد فروق بين الممارسين لألعاب القوى وغير

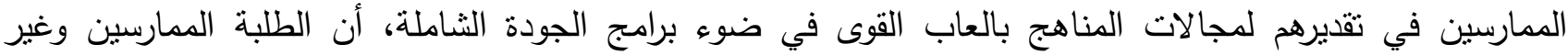

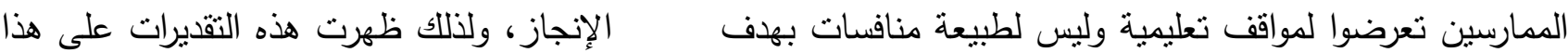

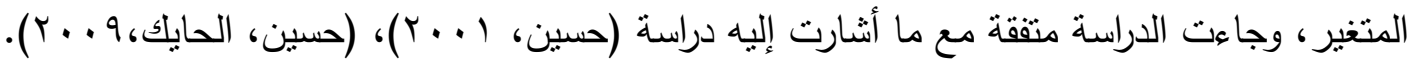




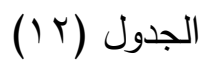

تحليل التباين الأحادي تبعاً لمتغير مستوى المادة لمنهاج العاب القوى

\begin{tabular}{|c|c|c|c|c|c|}
\hline قفيمة & المربعات & الحرية & المربعات & المجموعة & المتغيرات \\
\hline \multirow[t]{3}{*}{ Y.IV } & $r . \wedge 9$ & r & $V . \wedge 9$ & بين الدجموعات & \multirow[t]{3}{*}{ مجال الأهداف } \\
\hline & 1.20 & זr & MT.AY & داخل المجموعات & \\
\hline & & 1ro & & المجموع الكلي & \\
\hline \multirow[t]{3}{*}{$1 . .7$} & r.99 & r & $7.9 V$ & بين المجموعات & \multirow{3}{*}{ مجال المحتوى } \\
\hline & r.AT & Trt & $\varepsilon|r| r$. & داخل المجموعات & \\
\hline & & 150 & & المجموع الكلي & \\
\hline \multirow[t]{3}{*}{. Vo } & T.TV & r & $0.1 \pi$ & بين المجموعات & \multirow{3}{*}{ والأنشطة الأساليب } \\
\hline & E.To & 1Tr & $7 \leqslant . .9$. & داخل المجموعات & \\
\hline & & 150 & & الدجموع الكلي & \\
\hline \multirow[t]{3}{*}{..$r T$} & $1.1 r$ & r & $r . r$. & بين المجموعات & \multirow[t]{3}{*}{ مجال التقويم } \\
\hline & E. ro & irt & TVQ.Yo & داخل المجموعات & \\
\hline & & 150 & & المجموع الكلي & \\
\hline
\end{tabular}

قيمة ف الجدولية عند مستوى الدلالة . ... = 19.19.

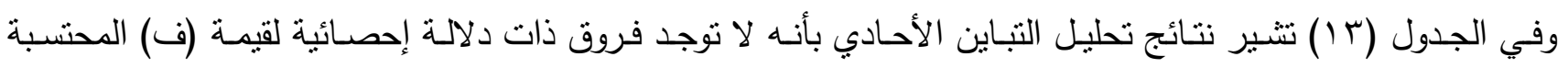

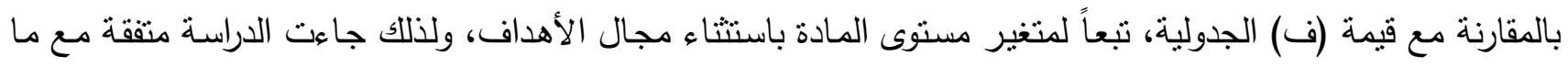

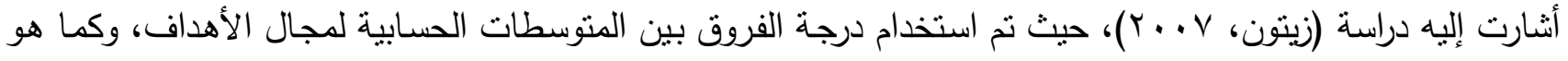

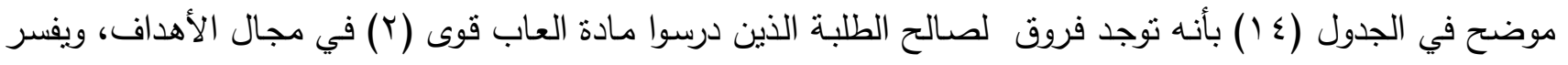

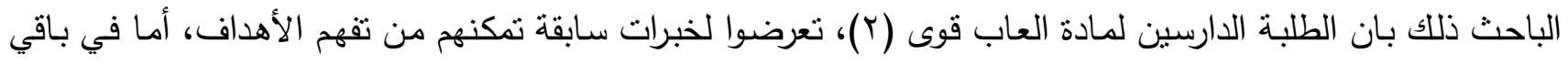

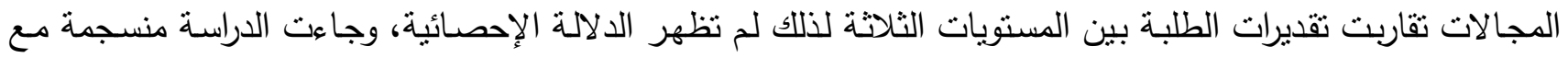

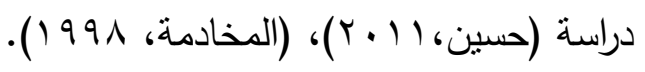




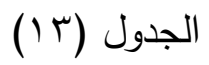

درجة الفروق بين المتوسطات الحسابية تبعاً لمتغير مستوى المادة الدراسية

\begin{tabular}{|c|c|c|c|c|c|}
\hline \multicolumn{2}{|c|}{ الفرق بين المجموعات } & المتوســــ & عـــــــدد & المجموعات & الاختبارات \\
\hline r & 1 & الحسابي & الطلاب & & مجــــــال \\
\hline. $.1 r$ & - & $r . r v$ & ה & العاب قوى ( ) & الأهداف \\
\hline - & - & $r . .1$ & r & العاب قوى (Y) & \\
\hline
\end{tabular}

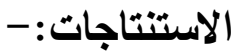

من خلال مناقثة النتائج نوصل الباحث إلى الاستتناجات الثنالية:-

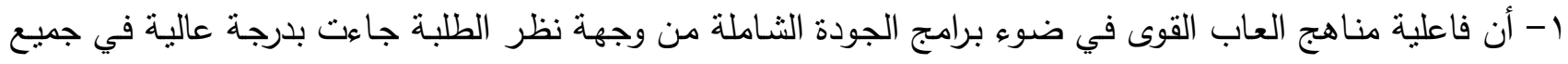

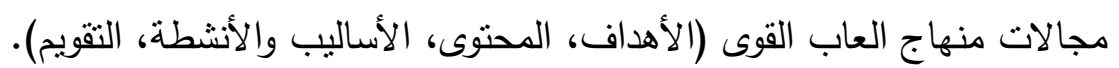

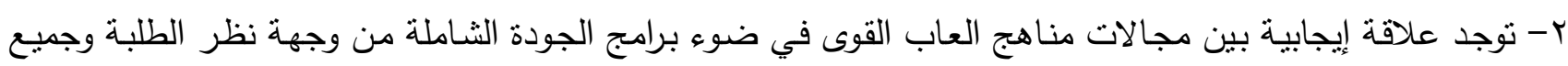

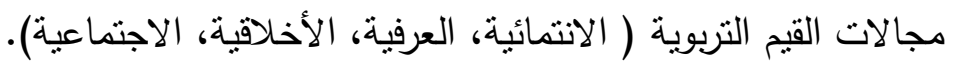

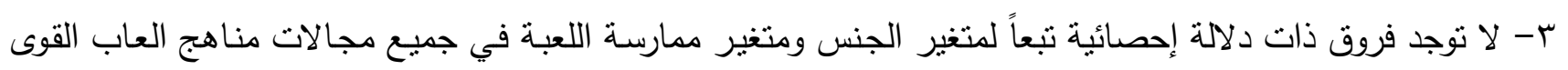

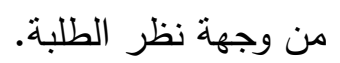
ع - وجود فروق ذات دلالة إحصائية بين المتوسطات الحسابية تبعاً لمتغير مسنوى المادة في مجال الأهداف ولصالح الطلبة الذين درسوا العاب القوى(؟).

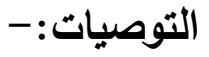

من خلال عرض نتائج الدراسة ومناقشتها، وما توصلت إليه من استتناجات يرى الباحث تقديم التوصيات الآتية:-

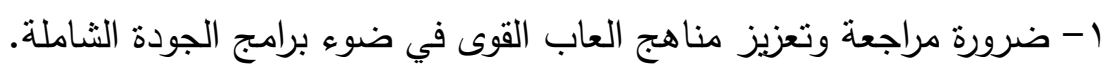

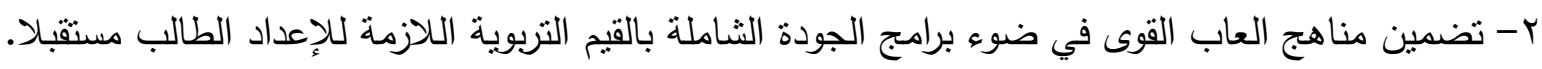

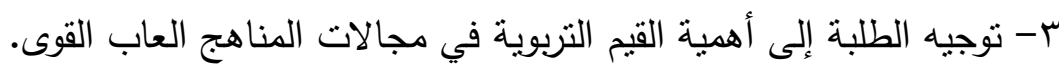

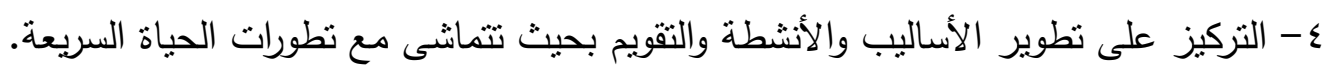
ه- إجراء دراسات مشابهة على العاب فردية أخرى. 


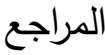

\section{أولأ : المراجع العربية}

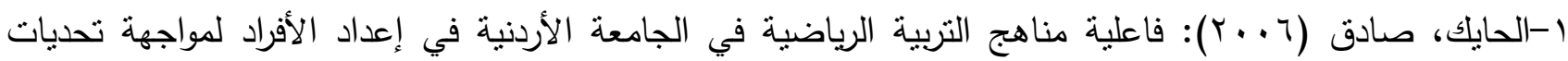
العصر، المؤتمر العلمي الثامن عرش، مناهج التعليم وبناء الإنسان العربي جمعية المناهج وطرق التدريس، المجلد؟ ،

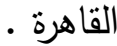

r-الخطيب، منذر ( ( . . r): المناهج التربوية ومناهج التربية الرياضية، الأكاديمية الرياضية العراقية، بغداد. ץ-الخلف، معين (1997): القيم التربوية الواجب توفرها لاى طلبة كليات التربة الرياضية من وجهة نظرهم ، رسالة ماجستير غير منشوره، جامعة اليرموك، الأردن .

ع-الديري، علي (r + . r): المناهج المعاصرة في التربية الرياضية وتطبيقاتها العملية ، جامعة اليرموك ، الأردن. ه-الديري، علي (r99 (1): دراسة تحليلية لتقويم مناهج التربية الرياضية في دولة الإمارات العربية المتحدة ، المجلة العلمية في التربية البدنية الرياضية، جامعة حلون • צ-المخادمه، عبداله 991 1: القيم التربوية لدى لاعبي المنتخبات الوطنية في الأردن رسالة ماجستير غير منشورة،

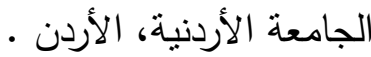

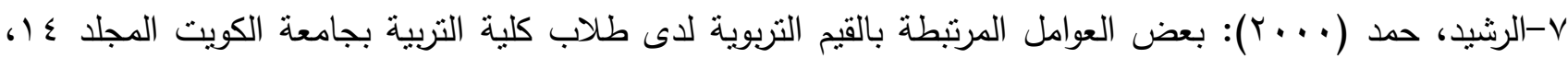

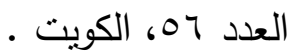
^-الرياض، علي والزغول، محمد وابو هرجه، محمد (0 . ب): مناهج التربية الرياضية المدرسية الموجة قيميا في مواجهة انعكاسات عصر العولمة ، الطبعة الأولى ، مركز الكتاب للنشر ، مصر .

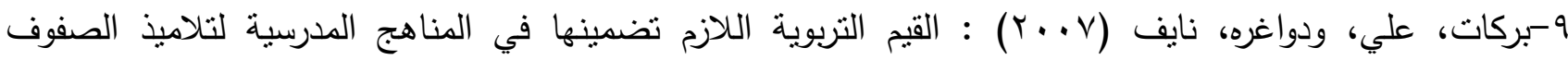

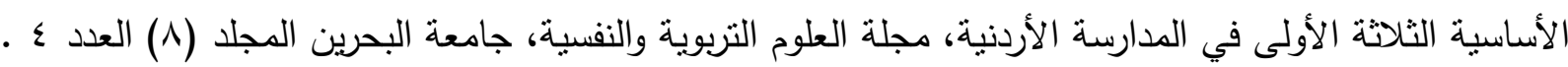

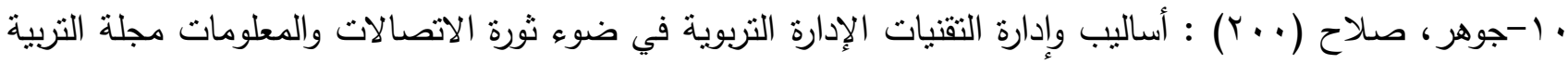
كلية التربية ، جامعة الأزهر ماند، 1) ا-حسين، عبدالسلام، (11 (r) : ثقويم فاعلية مجالات منهاج الألعاب الجماعية في ضوء الجودة الثاملة وعلاقتها

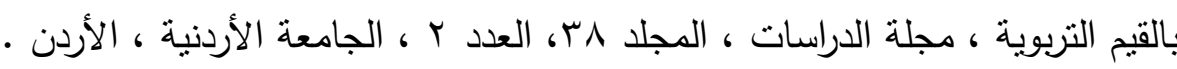
r r-حسين، عبد السلام، والحايك، صادق (9 . . r) : مدى فاعلية مناهج الكرة في ضوء برامج الجودة الشاملة وعلاقتها بالقيم التربوية ، مجلد المؤتمر العلمي لعلوم التربية البدنية والصحية ، دور النقافة البدنية في توسيع قاعدة الممارسات الرياضية ، جامعة السابع من ابريل ، لبييا .

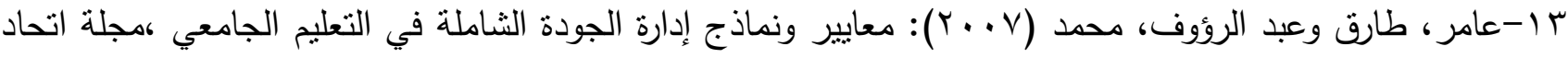
الجامعات العربية ، عدد خاص ، العدد ع. 
رائد محمد الرقاد

ع ا-عامر، رشيد (T + . ץ): فاعلية دور مناهج كليات التربية الرياضية في تتمية الأحكام القيمية لدى طلابها ، المؤتمر العلمي الدولي الخامس علوم الرياضية في عالم متغير، المجلد الثاني، الأردن.

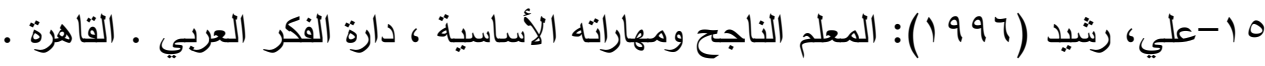
جا-محمد، ابراهيم وآخرون ( (. . ץ): دور كليات التربية الرياضية في تتمية القيم لدى طلابها ، مجلة بحوث التربية الرياضية ، كلية التربية الرياضية للبنين الزقازيق ـ البمان V V ا-مطاوع، وسام (1) (1) ): دور كليات البنات في تدعيم بعض القيم الاجتماعية والدينية لدى طالباتها، رسالة ماجستير غير منشورة، كلية لبنان، جامعة عين شمس.

\section{المراجع : ألأجنبية}

18- Hamelin, Daniel. (1982). Les objectives pedagogues' en formation 67 initials et en formation continues, Paris: Ed, E.S.F.

19-Goudas, M., Dermitzaki, I., \& Danish, S. (2006) The Effectiveness of Teaching a life skills Program in a Physical Education Context, European Journal of Physical of Education, XXI (4), 429-438.

20- kerber, A. (1994). Educational issues in changing society. N, Y, Detarit: Wayne state University.

21- Navartnam, K. \& O'Connor, R. (1993). Quality assurance in vocational of education, education-meeting the needs of the minute's vocational aspect, Journal of Education, (2), $59-75$.

2r-Woodhouse, B. David, J. (2005). Introduction to Australian Universities Quality Agency and Quality Audit, Lecture, Accreditation Council. 


\section{الملخص باللغة العربية}

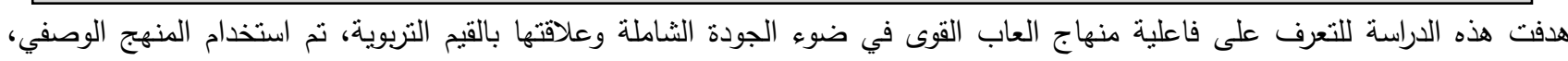

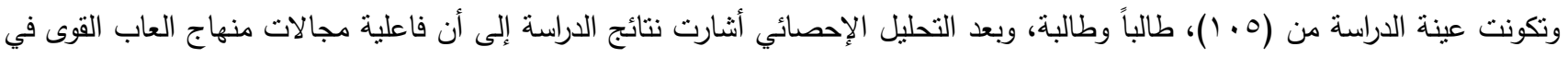

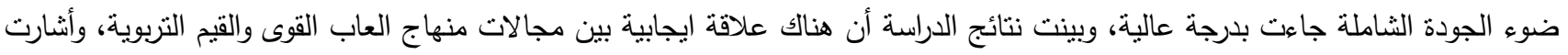

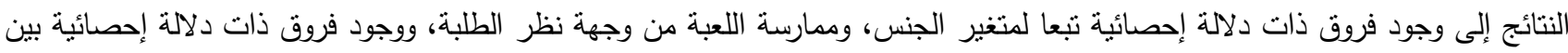

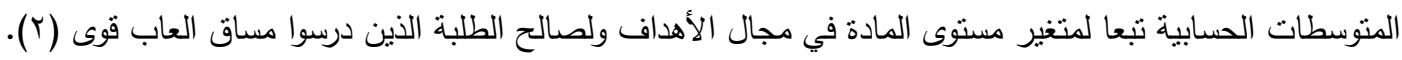

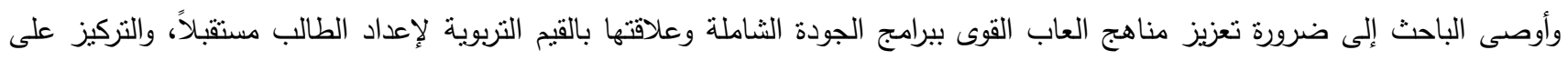

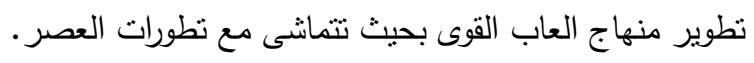
الكلمات المفتاحية:- المنهاج، القيم، العاب القوى.

\section{الملخص باللغة الإنجليزية}

The Effectiveness of the Curriculum of Athletics in Light of Comprehensive Quality and its Relationship to the Educational Values from the Perspective of the students of the Hashemite University

Dr. Raid Mohammed Al-Ragad

This study aimed at identifying the effectiveness of the curriculum of Athletics in light of comprehensive quality and its relationship to the educational values. The paper used the descriptive approach and a study sample consisted of (105) students. And after a statistical analysis, the study results indicated that the effectiveness of the areas of the curriculum of Athletics in light of comprehensive quality achieved a high degree. The study results illustrated that there is a positive relationship between the areas of the curriculum of Athletics and the educational values. The results pointed out to statistical differences according to the variable of gender, and the practice of the game from the perspective of students, and the existence of statistical differences among the averages according to the variable of the level of the study course in the field of goals and for the benefit of students who studied the course Athletics.

(2) The researcher recommended the need to strengthen the curriculum of Athletics in the programs of comprehensive quality and its relationship with the educational values to prepare the student for the future. $\mathrm{He}$ also recommended to focus on the development of the curriculum of Athletics to be able to stay updated with the world's developments.

Key words: - Curriculum, values, athletics 